\title{
Thrust Performance of Rotary-Valved Four-Cylinder Pulse Detonation Rocket Engine*
}

\author{
Ken MatsuoKa, ${ }^{1)}$ Ryuki Sakamoto, ${ }^{2)}$ Tomohito Morozumi, ${ }^{2)}$ Jiro Kasahara, ${ }^{1)}$ \\ Akiko MATSUO, ${ }^{3)}$ and Ikkoh FUNAKI ${ }^{4)}$ \\ ${ }^{1)}$ Department of Aerospace Engineering, Nagoya University, Aichi 464-8603, Japan \\ ${ }^{2)}$ Department of Engineering Mechanics and Energy, University of Tsukuba, Ibaraki 305-8577, Japan \\ ${ }^{3)}$ Department of Mechanical Engineering, Keio University, Kanagawa 223-8521, Japan \\ ${ }^{4)}$ JAXA Institute of Space and Astronautical Science, Kanagawa 252-5210, Japan
}

\begin{abstract}
We designed a rotary valve for a multi-cylinder pulse detonation rocket engine (PDRE), and constructed a greatly simplified rotary-valved four-cylinder PDRE (inner diameter and length of detonation tube: $37 \mathrm{~mm}$ and 1,600 mm, respectively). The partial-fill effect of a propellant in a multi-cylinder PDRE under high-frequency operation was investigated. The suctioned-air fill fraction was estimated using the model of Sato et al., which is a semiempirical formula for the partialfill effect of a propellant based on two-dimensional numerical analysis [Sato et al., Journal of Propulsion and Power, Vol. 22 , No. 1, 2006, pp. 64-69]. A maximum propellant-based specific impulse of $251 \mathrm{~s}$ and a time-averaged thrust of $242 \mathrm{~N}$ were achieved using $\mathrm{C}_{2} \mathrm{H}_{4}-\mathrm{O}_{2}$ as the propellant and an operation frequency of $129.6 \mathrm{~Hz} /$ tube (fill pressure: $1 \mathrm{~atm}$ ). The maximum operation frequency was $160.3 \mathrm{~Hz} /$ tube $(641.2 \mathrm{~Hz} /$ all tubes $)$.
\end{abstract}

Key Words: Pulse Detonation Engine, Pulse Detonation Rocket Engine, Rotary Valve

\section{Nomenclature}

$A_{\mathrm{t}}$ : cross-sectional area of the detonation tube

$D_{\mathrm{CJ}}$ : Chapman-Jouguet velocity

$f_{\mathrm{D}}$ : number of occurrences of detonation wave per second

$f_{\text {exp }}$ : experimental operation frequency per tube

$f_{\text {motor }}$ : setup rotation rate of the rotary motor

$f_{\text {set }}$ : setup operation frequency per tube

$F_{\text {exp }}$ : time-averaged thrust

$g$ : gravitational acceleration

$I_{\text {exp }}$ : experimental total impulse

$I_{\mathrm{sp} \text {, exp }}$ : experimental propellant-based specific impulse

$I_{\text {sp, exp, all }}$ : experimental total-gas-based specific impulse

$\dot{m}$ : mass flow rate

$\dot{m}_{\text {cycle }}$ : mass flow rate during each supply process

$N_{\mathrm{lh}}$ : number of long holes of the rotating disk per $360^{\circ}$ turn for each gas-supply port

$N_{\mathrm{t}}$ : number of detonation tubes

$p$ : absolute pressure

$R$ : gas constant

$S_{\text {input }}$ : spark input signal

$S_{\text {output }}$ : spark output signal

$t_{\text {ope }}$ : duration of operation

$u$ : gas-flow velocity inside detonation tube

$T$ : temperature

$V$ : volume

$\alpha$ : dilution coefficient

$\eta$ : success rate of detonation wave $\left(0.9 D_{\mathrm{CJ}}\right)$

(C) 2015 The Japan Society for Aeronautical and Space Sciences *Received 21 January 2014; final revision received 14 January 2015; accepted for publication 15 January 2015. $\kappa$ : open ratio of gas-supply port in experiments

$\lambda$ : open ratio of gas-supply port

$\chi$ : ratio of burned gas volume to tube volume after excluding propellant and purge gas

$\theta$ : rotation angle of rotary valve

$\phi$ : equivalence ratio

$\gamma$. specific heat ratio

$\rho$ : gas density

$\psi$ : gas fill fraction (gas fill volume/tube volume) Subscripts

a: ambient

air: air

b: burned gas

$\mathrm{CV}$ : constant-volume combustion

$\mathrm{d}$ : driven gas

e: exhaust

f: fuel

FF: propellant fully filled

i: purge gas

I: average of purge gases

o: oxidizer

p: propellant

PF: propellant partially filled

s: supply

t: single detonation tube

\section{Introduction}

A detonation wave ${ }^{1)}$ is a hypersonic combustion wave that is sustained by the interaction between the leading shock wave and the heat release of a chemical reaction. A pulse detonation engine (PDE) can achieve a significant propulsive force and perform mechanical work via the generation of a 
high-frequency detonation wave. ${ }^{2-5)}$ With a simplified PDE setup, that is, when viscosity and heat conduction are neglected and a cylindrical combustor (detonation tube) is filled with propellant at ambient pressure and a detonation wave is initiated instantaneously, a pulse detonation rocket engine (PDRE) using $\mathrm{H}_{2}-\mathrm{O}_{2}$ propellant can achieve a propellantbased specific impulse of $186 \mathrm{~s}$ under a fill pressure of $1 \mathrm{~atm}$, while an air-breathing PDE using hydrogen fuel can achieve a fuel-based specific impulse of 4,215 $\mathrm{s}$ under a fill pressure of $1 \mathrm{~atm}$, as achieved in the gas dynamics analysis of Endo et al. ${ }^{6}$ ) These results are in good agreement with those of single-pulse experiments conducted by Zhdan et al., ${ }^{7)}$ Cooper et al., ${ }^{8)}$ and Wintenberger et al., ${ }^{9)}$ and those of $16 \mathrm{~Hz}$ multi-pulse experiments using $\mathrm{H}_{2}$-air propellant by Schauer et al. ${ }^{10)}$ (3,800-4,450 s, fill pressure: $\left.1 \mathrm{~atm}\right)$. Moreover, a PDE can achieve a very high specific impulse by partial filling of the propellant, a nozzle and an ejector. The partial filling of the propellant in a detonation tube is the simplest way to increase the specific impulse. ${ }^{11-16)}$ In addition to the propellant in the detonation tube, purge gas, burned gas and air suctioned from the open end after the high-pressure burned gas has been blown down are compressed by a shock wave, and the specific impulse is increased by the compressed gases. In particular, the partial-fill effect is strongly dependent on the amount of suctioned air, because the air density of $\rho_{\text {air }} \approx 1.20 \mathrm{~kg} / \mathrm{m}^{3}$ at $1 \mathrm{~atm}$ and $300 \mathrm{~K}$ is higher than the burned gas density of $\rho_{\mathrm{b}} \approx 0.104$ $\mathrm{kg} / \mathrm{m}^{3}$ at $1 \mathrm{~atm}$. This partial-fill effect has been confirmed in multi-pulse operation. Schauer et al. ${ }^{10)}$ investigated the partial-fill effect by varying the fill fraction of $\mathrm{H}_{2}$-air propellant $\left(\psi_{\mathrm{p}}\right.$, propellant volume/detonation tube volume) and found that the specific impulse was increased by decreasing the propellant fill fraction. In their test, a fuel-based maximum specific impulse of $7,100 \mathrm{~s}$ was achieved at $\psi_{\mathrm{p}}=0.3$ under the operation frequencies $f_{\text {set }}=12 \mathrm{~Hz}$ and $16 \mathrm{~Hz}$ and a fill pressure of $1 \mathrm{~atm}$. Kasahara et al. ${ }^{15)}$ measured the specific impulse of $\mathrm{C}_{2} \mathrm{H}_{4}-\mathrm{O}_{2}$ propellant in multi-pulse experiments, and a maximum specific impulse of $305 \mathrm{~s}$ (propellantpurge-gas-based) was achieved at $\psi_{\mathrm{p}}=0.13\left(f_{\text {set }}=10 \mathrm{~Hz}\right.$, fill pressure: $1 \mathrm{~atm})$. In these previous studies, the thrust performance of a PDE under single-pulse and low-frequency operation was investigated.

The challenge in making practical use of a PDE is to increase the thrust-to-weight ratio. The thrust-to-weight ratio of a PDE is low because of the intermittent combustion cycle. Increasing the thrust density in each detonation tube and the use of multiple cylinders are required to increase the thrust-to-weight ratio. Increasing the thrust density under high-frequency operation is achieved by enhancing the deflagration-to-detonation transition (DDT), and many studies have been performed to attempt such an enhancement. ${ }^{17,18)}$ The use of multiple cylinders requires the development of an intermittent flow generation valve that is appropriate for a multi-cylinder PDE. A continuous propellant supply is only possible when the number of detonation tubes is increased and the phase of the PDE cycle at each detonation tube is different from that of the other detonation tubes. The perfor- mance requirement for the valve to accomplish this operation is very high. Increasing the number of detonation tubes while maintaining a simplified structure, a high mass flow rate at a high operation frequency and a low total pressure loss across the valve are all required to increase the thrust-toweight ratio. Many valves for use with a PDE have been proposed. ${ }^{19-24)}$ The rotary valve proposed by Bussing ${ }^{23)}$ satisfies the performance requirements described above and is appropriate for use with a multi-cylinder PDE. Matsuoka et al. ${ }^{24)}$ developed a rotary valve appropriate for use with a rocket system based on Bussing's valve, and they investigated the fluid motion and thrust performance of a rotary-valved single-cylinder PDRE by performing optical and thrust measurements. However, the operation characteristics and thrust performance of the rotary-valved multi-cylinder PDE developed by Bussing were not made public, and the rotary valve for a rocket system must supply three different gases to the detonation tubes while maintaining a simplified structure.

We upgraded the valve of Matsuoka et al. ${ }^{24)}$ and applied it to a four-cylinder PDRE while maintaining a simplified structure, and verified the continuous gas supply and the increase in thrust/valve mass. Bussing's valve was appropriate to use with an air-breathing system, and either a premixed propellant was supplied to the detonation tubes using a single disk or three different gases were supplied to a single predetonator. In contrast, our valve can supply three different gases into a number of detonation tubes using a single rotating disk. The partial-fill effect at high operation frequencies ( $f_{\text {set }}=40-160 \mathrm{~Hz}$ ) was shown, and the elements of the driven gases in multi-pulse operation were estimated using the model proposed by Sato et al. ${ }^{25)}$ The bubble model, which estimates the upper limit of the partial fill effect, ${ }^{13}$ ) was applied to multi-pulse operation, and the results obtained with the model were compared with experimental results.

\section{Experiment}

\subsection{Design of the rotary valve}

Figure 1 shows a schematic of the rotary valve for a fourcylinder PDRE developed in the present study. The valve is composed of a top cover, a casing and a rotating disk. The

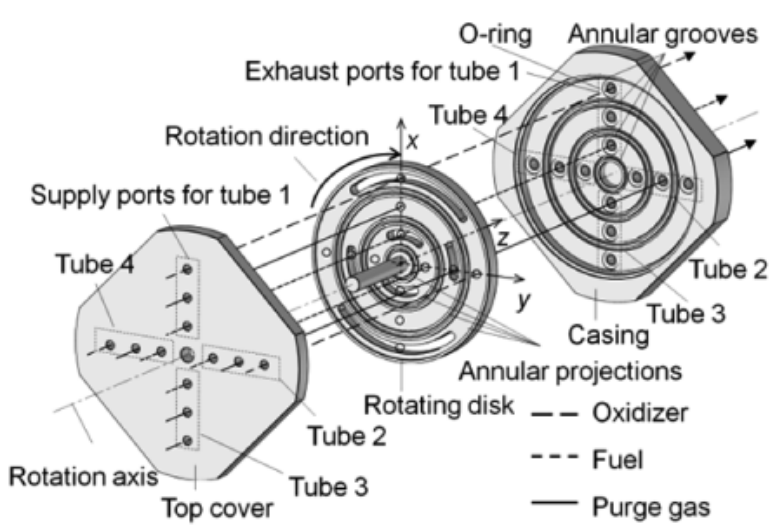

Fig. 1. Schematic of the rotary valve for a multi-cylinder PDRE (four-cylinder PDRE). 


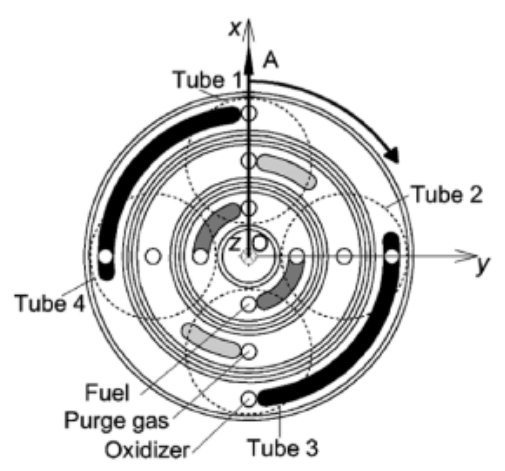

Fig. 2. Relative positions of rotating disk, gas-supply ports and detonation tubes (state 0 for tubes 1 and $3, \theta=0^{\circ}$ ).

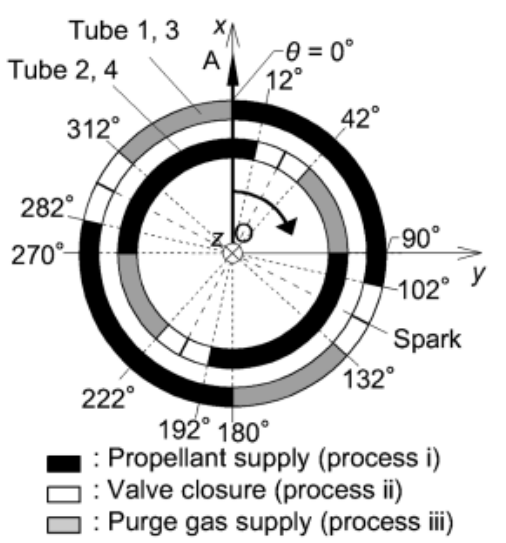

Fig. 3. Relationship between rotation angle and each PDRE process; outer circle: tubes 1 and 3, inner circle: tubes 2 and 4 .

Table 1. Conditions of thrust measurements.

\begin{tabular}{|c|c|c|c|c|c|c|}
\hline $\begin{array}{c}\text { Shot } \\
\text { number }\end{array}$ & $\begin{array}{c}\text { Motor } \\
\text { frequency } \\
f_{\text {motor }} \\
{[\mathrm{Hz} / \text { tube }]}\end{array}$ & $\begin{array}{l}\text { Operation } \\
\text { frequency } \\
\quad f_{\text {set }} \\
{[\mathrm{Hz} / \text { tube }]}\end{array}$ & $\begin{array}{c}\text { Detonation } \\
\text { frequency } \\
f_{\mathrm{D}} \\
{[\mathrm{Hz} / \text { all tubes }]}\end{array}$ & $\begin{array}{c}\text { Propellant supply } \\
\text { pressure } \\
p_{\mathrm{s}, \mathrm{p}} \\
{[\mathrm{MPa}]}\end{array}$ & $\begin{array}{c}\text { Purge gas supply } \\
\text { pressure } \\
p_{\mathrm{s}, \mathrm{i}} \\
{[\mathrm{MPa}]}\end{array}$ & $\begin{array}{c}\text { Duration of } \\
\text { operation } \\
t_{\text {ope }} \\
{[\mathrm{ms}]}\end{array}$ \\
\hline T-1 & 20 & 40 & 160 & 2.0 & 2.8 & 2,000 \\
\hline T-2 & 35 & 70 & 280 & 2.0 & 3.0 & 2,000 \\
\hline T-3 & 50 & 100 & 400 & 2.0 & 3.0 & 2,000 \\
\hline T-4 & 75 & 130 & 520 & 2.0 & 3.0 & 2,000 \\
\hline T-5 & 80 & 160 & 640 & 2.0 & 3.0 & 2,000 \\
\hline
\end{tabular}

rotating disk is inserted into the space between the top cover and the casing, and the external torque is input from a rotating shaft attached to the rotating disk. The top cover and casing have three gas-supply ports for each detonation tube. The rotating disk has long through-holes corresponding to each gas. When the rotating disk turns and these long holes overlap with the gas-supply ports, each gas is supplied into the detonation tube. This single valve can thus supply fuel, oxidizer and purge gas into a number of detonation tubes. To avoid gas mixing in the valve and gas leakage from sliding surfaces, we used O-rings, an annular labyrinth seal mechanism and silicone oil. ${ }^{24)}$

As shown in Fig. 1, a Cartesian coordinate system was chosen to express the system's operation. The origin of this coordinate system is the center of the rotating disk. The positive direction of the $z$-axis is the direction of gas blowout, and the rotating disk turns clockwise as viewed from the topcover side. The detonation tube set up on the positive $x$-axis was specified as tube 1 , and the other tubes were specified as tubes $2-4$ in the direction of rotation.

\subsection{Geometry of the rotating disk}

Figure 2 shows the relative positions of the rotating disk, gas-supply ports and detonation tubes. The solid concentric circles in Fig. 2 show the labyrinth-seal mechanism (grooves). The four non-concentric circles are the detonation tubes installed downstream of the rotary valve. The arrowtipped line, OA, shows the baseline, which was fixed in the rotating disk. We defined state 0 as the state immediately before propellant is first supplied to tubes 1 and 3 . The rotation angle, $\theta$, was defined as the angle difference from state 0 .
Figure 3 shows the relationship between the rotation angle, $\theta$, and each PDRE process (propellant supply, valve closure, purge gas supply). The outer circle shows the PDRE cycle for tubes 1 and 3 , and the inner circle shows the PDRE cycle for tubes 2 and 4. The position of the baseline in Fig. 3 shows state 0 for tubes 1 and 3. As shown in Fig. 3, the PDRE cycle occurred in the same phase in tubes 1 and 3, while the PDRE cycle in tubes 2 and 4 occurred after a delay of $90^{\circ}$. A continuous gas supply was achieved in the oxidizer port. The rotating disk was subjected to a load due to the pressure gradient when the disk interrupted the flow or the high-pressure burned gas blew out. When the center of this load was not equal to the center of rotation, the rotating disk turned eccentrically. As shown in Fig. 3, the PDRE cycle occurred in the same phase in two point-symmetric detonation tubes, and eccentric rotation was not possible.

The time ratio, $\lambda$, of the processes comprising a PDRE cycle was $\lambda_{\mathrm{o}}=\lambda_{\mathrm{f}}=56 \%$ for propellant supply, $17 \%$ for valve closure and $\lambda_{i}=27 \%$ for purge gas supply. The spark plug sparked when all the supply ports were closed under all conditions. The disk had rotated by a half turn from state 0 by the end of process iii, and in that time one PDRE cycle was completed. A full $360^{\circ}$ turn of the rotating disk thus produced two PDRE cycles for each detonation tube. As shown in Table 1, the operation frequency per detonation tube, $f_{\text {set }}$, and the number of detonation occurrences, $f_{\mathrm{D}}$, were calculated using $f_{\text {set }}=f_{\text {motor }} N_{\mathrm{lh}}$ and $f_{\mathrm{D}}=f_{\text {motor }} N_{\mathrm{lh}} N_{\mathrm{t}}$, respectively, where $f_{\text {motor }}$ is the rotation frequency of the rotary motor, $N_{\mathrm{lh}}=2$ is the number of open gas-supply ports during a $360^{\circ}$ turn of the rotating disk and $N_{\mathrm{t}}=4$ is the number 


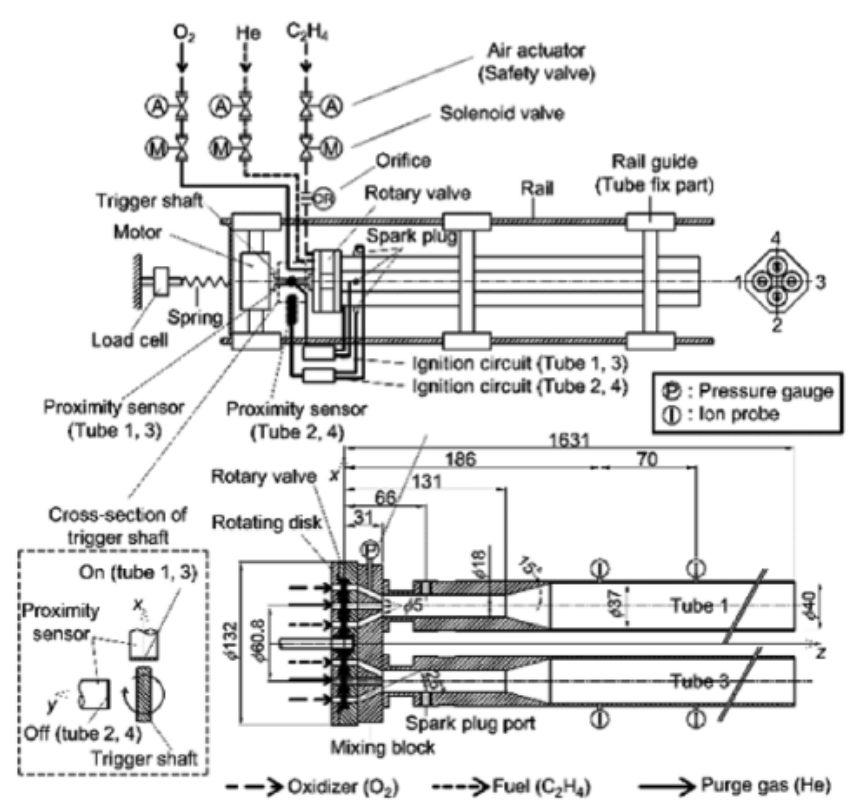

Fig. 4. Schematic diagram of the experimental apparatus (top) and crosssection of a four-cylinder PDRE (bottom).

of detonation tubes.

The angle at which the supply port reached the fully open state or the fully closed state varied because the distances between the origin and the center of each supply port were different. This angle was $6.3^{\circ}$ for the oxidizer, $9.4^{\circ}$ for the purge gas and $18.7^{\circ}$ for the fuel. During the opening and closing processes, there was an abrupt expansion in the flow passage due to the rotating disk, causing a total pressure loss. As in the model of Matsuoka et al., ${ }^{24)}$ in our experimental setup, the time-averaged total pressure loss ratio was not dependent on the operation frequency and was $6 \%$ for the oxidizer, $9 \%$ for the purge gas and $18 \%$ for the fuel.

\subsection{Experimental setup and conditions}

We carried out thrust measurements and measured the mass flow rate, thrust and specific impulse of our four-cylinder PDRE. Figure 4 shows schematic diagrams of the thrust experiment apparatus and a cross-section of the PDRE, and Fig. 5 shows a photograph of the four-cylinder rotary-valved PDRE. Three different gases were supplied into the rotary valve through the air actuator and solenoid valve. The duration of operation was controlled by this solenoid valve, which was continuously in an open state during operation. An orifice was installed upstream of the fuel supply port to control the equivalence ratio. The intermittent flow generated by the rotary valve was supplied into each detonation tube. The rotary valve was turned by an electromagnetic motor, and the rotation shaft had a spark trigger (trigger shaft). Two differently timed sparks were produced by two proximity sensors and the trigger shaft. As shown on the left side of Fig. 4, each proximity sensor detected the surface of the trigger shaft and sent a spark input signal to an ignition circuit, which sent a high voltage to a spark plug. The detection distance of the proximity sensor was $2.5 \mathrm{~mm}$.

The PDRE and motor were mounted on a rail guide and could slide along it. When thrust was generated, the appara-

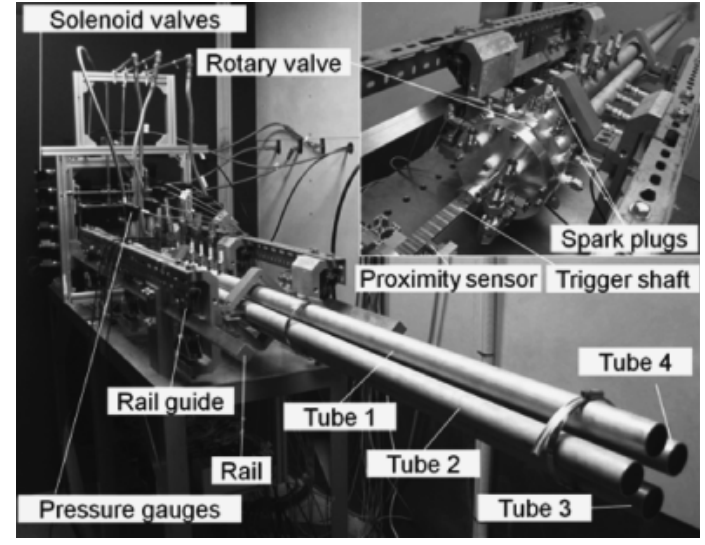

Fig. 5. Photograph of the rotary-valved four-cylinder PDRE.

tus slid on the rail guide and the equivalent load was applied to the load cell. A spring was mounted between the load cell and the PDRE to smooth the impulse generated by the detonation wave. As shown at the bottom of Fig. 4, the diameter of each supply port was $5 \mathrm{~mm}$, and the oxidizer and fuel were supplied into the detonation tube at an angle of $\pm 25^{\circ}$ with respect to the detonation tube axis. The central axis of the purge gas port was identical to the axis of each detonation tube, and the purge gas was supplied from the closed-tube end. Pressure gauges were mounted in the pipe between the rotary valve and the detonation tube to confirm valve operation. The position of the closed-tube end was $z_{\text {wall }}=31 \mathrm{~mm}$, while that of the open-tube end of the combustor was $z=1,631 \mathrm{~mm}$. The detonation tube length and volume were $1,600 \mathrm{~mm}$ and $V_{\mathrm{t}}=1.62 \mathrm{~L}$, respectively. The spark plugs were installed at $z=66 \mathrm{~mm}$. The inner diameter of the detonation tube was expanded from $18 \mathrm{~mm}$ to $37 \mathrm{~mm}$ by tapering (angle of aperture of $15^{\circ}$ ) from $z=131 \mathrm{~mm}$. The velocities of the cyclic combustion wave were measured by four ion probes installed at $z=186 \mathrm{~mm}, 256 \mathrm{~mm}, 326 \mathrm{~mm}$ and $396 \mathrm{~mm}$. Table 1 shows the experimental conditions. The experimental setup operation frequencies, $f_{\text {set }}$, were $40 \mathrm{~Hz}, 70 \mathrm{~Hz}, 100 \mathrm{~Hz}, 130 \mathrm{~Hz}$ and $160 \mathrm{~Hz}$. The ethylene and oxygen supply pressures were constant at $p_{\mathrm{s}, \mathrm{p}}=2.0$ $\mathrm{MPa}$. Therefore, the propellant fill fraction was varied while the propellant mass flow rate remained constant. The helium supply pressure was determined experimentally. The duration of the operation was $t_{\mathrm{ope}}=2,000 \mathrm{~ms}$, and thrust measurements were carried out three times to ensure the repeatability of the experiment.

\subsection{Calculation of fill fraction, time-averaged thrust and specific impulse}

For the method used to calculate the mass flow rate, $\dot{m}$, see Matsuoka et al. ${ }^{19)}$ In the actual filling process of the propellant and purge gas, propellant and purge gas flow into the detonation tubes. The fill fractions were estimated assuming that the flow was an incompressible steady flow and that the pressure and temperature were constant under ambient conditions. The mass flow rate of each supply process, $\dot{m}_{\text {cycle }}$, was obtained using the time-averaged mass flow rate, $\dot{m}\left(\dot{m}_{\mathrm{p}}\right.$, $\left.\dot{m}_{\mathrm{i}}\right)$, the duration ratio per PDE cycle, $\lambda\left(\lambda_{\mathrm{p}}=0.56\right.$, 
$\left.\lambda_{\mathrm{i}}=0.27\right)$, and the number of detonation tubes, $N_{\mathrm{t}}=4$.

$$
\dot{m}_{\text {cycle }}=\frac{\dot{m}}{N_{\mathrm{t}} \lambda}
$$

Assuming that the flow was an incompressible steady flow, that the pressure and temperature were constant under ambient conditions and that the gases were perfect gases, the flow speed (filling speed) was defined as

$$
u=\frac{\dot{m}_{\text {cycle }}}{\rho A_{\mathrm{t}}}=\frac{\dot{m}}{N_{\mathrm{t}} \lambda A_{\mathrm{t}}} \frac{R T_{\mathrm{a}}}{p_{\mathrm{a}}}
$$

where the average values were $\dot{m}_{\mathrm{p}}=99.7 \pm 1.3 \mathrm{~g} / \mathrm{s}$ and $R_{\mathrm{p}} \approx 268.1 \mathrm{Jkg}^{-1} \mathrm{~K}^{-1}$ for the propellant, and $\dot{m}_{\mathrm{i}}=14.1 \pm$ $1.7 \mathrm{~g} / \mathrm{s}$ and $R_{\mathrm{i}} \approx 2,078.6 \mathrm{Jkg}^{-1} \mathrm{~K}^{-1}$ for the purge gas. The ambient pressure and temperature were $p_{\mathrm{a}}=101.2 \pm 0.1$ $\mathrm{kPa}$ and $T_{\mathrm{a}}=293 \pm 2 \mathrm{~K}$, respectively. As shown in Fig. 4, the cross-sectional area of the detonation tube, $A_{\mathrm{t}}$, varied with the filled distance in the range of $A_{\mathrm{t}}=284 \mathrm{~mm}^{3}$ to $1,075 \mathrm{~mm}^{3}$. Using Eq. (2), the filling speed of the propellant (purge gas) was estimated to be $u_{\mathrm{p}}=122 \pm 1 \mathrm{~m} / \mathrm{s} \quad\left(u_{\mathrm{i}}=\right.$ $277 \pm 35 \mathrm{~m} / \mathrm{s}$ ) where the inner diameter of the tube was $18 \mathrm{~mm}$ and $u_{\mathrm{p}}=32 \pm 1 \mathrm{~m} / \mathrm{s}\left(u_{\mathrm{i}}=73 \pm 9 \mathrm{~m} / \mathrm{s}\right)$ where the inner diameter was $37 \mathrm{~mm}$. The corresponding range of Mach numbers was $M_{\mathrm{p}}=0.10-0.38 \quad\left(M_{\mathrm{i}}=0.07-0.28\right)$. The filled volume at the end of the supply process $(t=\lambda / f)$ was obtained using the tip position of the flow. The fill fractions $\psi_{\mathrm{p}}$ and $\psi_{\mathrm{i}}$ were defined as the ratio of the filled volume to the total volume of the detonation tube, $V_{\mathrm{t}}=1.62 \mathrm{~L}$.

The total impulse, $I_{\text {exp }}$, was given as

$$
I_{\exp }=\int_{t_{\text {start }}}^{t_{\text {stop }}} F_{\mathrm{lc}} \mathrm{d} t
$$

where $t_{\text {start }}$ is the time when the load cell output began to increase, and $t_{\text {stop }}$ is the point of intersection of the base $(0 \mathrm{~N})$ with the load cell output, $F_{\mathrm{lc}}$. The time-averaged thrust, $F_{\text {exp }}$, was expressed as

$$
F_{\exp }=\frac{I_{\text {exp }}}{t_{\text {stop }}-t_{\text {start }}}
$$

Finally, the propellant-based experimental specific impulse, $I_{\mathrm{sp} \text {, exp }}$, was obtained from the time-averaged thrust, $F_{\text {exp }}$, the oxidizer mass flow rate, $\dot{m}_{\mathrm{o}}$, the fuel mass flow rate, $\dot{m}_{\mathrm{f}}$, and gravitational acceleration, $g$, as follows:

$$
I_{\mathrm{sp}, \exp }=\frac{F_{\mathrm{exp}}}{g\left(\dot{m}_{\mathrm{o}}+\dot{m}_{\mathrm{f}}\right)}
$$

Similarly, the total-gas-based experimental specific impulse, $I_{\text {sp, exp, all, was obtained as }}$

$$
I_{\mathrm{sp}, \exp , \text { all }}=\frac{F_{\mathrm{exp}}}{g\left(\dot{m}_{\mathrm{o}}+\dot{m}_{\mathrm{f}}+\dot{m}_{\mathrm{i}}\right)}
$$

\subsection{Error evaluation}

For the experimental operation frequency obtained from the spark output signal, $f_{\text {exp }}$, and mass flow rate, $\dot{m}$, only the standard error of the mean, $\sigma$, was considered as the error, $\varepsilon$, as follows:

$$
\varepsilon=\sigma=\sqrt{\frac{\sum_{\mathrm{i}=1}^{n} \Delta_{\mathrm{i}}^{2}}{n(n-1)}}
$$

where $\Delta_{\mathrm{i}}$ is the residual error $\left(\Delta_{\mathrm{i}}=x_{\mathrm{i}}-\bar{x}\right), x_{\mathrm{i}}$ and $\bar{x}$ are the measured and averaged values, respectively, and $n$ is the number of tests $(n=3)$. For the error of the time-averaged thrust, $F_{\text {exp }}$, the standard error of the mean, $\sigma$, and the instrumental error of the load cell $( \pm 1.8 \mathrm{~N})$ as a systematic error, $\delta$, were considered, as follows:

$$
\varepsilon_{F_{\exp }}=\sqrt{\sigma_{F_{\exp }}^{2}+\delta_{F_{\exp }}^{2}}
$$

For the fill fraction, $\psi$, the error was obtained from the law of propagation of errors, as follows:

$$
\varepsilon_{\psi}=\sqrt{\left(\frac{\partial \psi}{\partial \dot{m}_{\exp }}\right)^{2} \varepsilon_{\dot{m}_{\exp }}^{2}+\left(\frac{\partial \psi}{\partial f_{\exp }}\right)^{2} \varepsilon_{f_{\exp }}^{2}}
$$

Similarly, the error of the propellant-based specific impulse, $I_{\mathrm{sp}, \exp }$, was expressed as

$$
\begin{aligned}
& \varepsilon_{I_{\text {sp }, \text { exp }}} \\
& =\sqrt{\left(\frac{\partial I_{\text {sp,exp }}}{\partial \dot{m}_{\mathrm{o}}}\right)^{2} \varepsilon_{\dot{m}_{\mathrm{o}}}{ }^{2}+\left(\frac{\partial I_{\mathrm{sp}, \exp }}{\partial \dot{m}_{\mathrm{f}}}\right)^{2} \varepsilon_{\dot{m}_{\mathrm{f}}}^{2}+\left(\frac{\partial I_{\mathrm{sp}, \exp }}{\partial F_{\exp }}\right)^{2} \varepsilon_{F_{\text {exp }}}^{2}}
\end{aligned}
$$

\section{Results and Discussion}

Table 2 shows the experimental results. Each value is the average of three iterations of the experiment. The experimental operation frequency obtained from the spark output signal, $f_{\text {exp }}$, was within $1 \%$ of the set frequency, $f_{\text {set }}$, and the stable rotation of the rotating disk was confirmed. The total-gas-based experimental specific impulse, $I_{\mathrm{sp} \text {, exp, all, was }}$ 86-89\% of the propellant-based specific impulse, $I_{\mathrm{sp}, \text { exp. }}$ A maximum specific impulse of $251 \mathrm{~s}$ and a time-averaged thrust of $242 \mathrm{~N}$ were achieved at an operation frequency of $129.6 \mathrm{~Hz}$ (T-4). The success rate, $\eta$, was defined as the number of combustion waves with velocity exceeding $0.9 D_{\mathrm{CJ}}$ divided by the total number of PDRE cycles $\left(t_{\text {ope }} \times f_{\text {set }}\right)$, averaged over all tubes.

\subsection{Monitoring of valve operation}

Figure 6 shows longitudinal profiles of the exhaust pressure of the oxidizer, $p_{\mathrm{e}, \mathrm{o}, 1}$, and purge gas, $p_{\mathrm{e}, \mathrm{i}, 1}$, and the spark output signal, $S_{\text {output, } 1}$, of tube 1 obtained by monitoring the valve. $S_{\text {input }}, \kappa_{\mathrm{o}}$ and $\kappa_{\mathrm{i}}$ in Fig. 6 are the spark input signal and the open ratios of the gas-supply ports of the oxidizer and purge gas, respectively. These valve sequences were predicted on the basis of time $t=0.0 \mathrm{~ms}$, at which $p_{\text {valve, }, 1}$ began to increase when the rotating disk turned at a constant rate.

At $t=0.0 \mathrm{~ms}\left(\theta=0^{\circ}\right)$, the oxidizer supply ports of tube 1 first began to open, and the exhaust pressure of the oxidizer, $p_{\mathrm{e}, \mathrm{o}, 1}$, increased gradually when the process went from state 
Table 2. Results of thrust measurements.

\begin{tabular}{|c|c|c|c|c|c|c|c|c|c|c|c|}
\hline $\begin{array}{c}\text { Shot } \\
\text { number }\end{array}$ & $\begin{array}{c}\text { Experimental } \\
\text { operation } \\
\text { frequency } \\
f_{\exp } \\
{[\mathrm{Hz} / \text { tube }]}\end{array}$ & $\begin{array}{l}\text { Propellant } \\
\text { mass flow } \\
\text { rate } \\
\dot{m}_{\mathrm{p}} \\
{[\mathrm{g} / \mathrm{s}]}\end{array}$ & $\begin{array}{c}\text { Purge gas } \\
\text { mass flow } \\
\text { rate } \\
\dot{m}_{\mathrm{i}} \\
{[\mathrm{g} / \mathrm{s}]}\end{array}$ & $\begin{array}{c}\text { Equivalence } \\
\text { ratio } \\
\phi \\
{[-]}\end{array}$ & $\begin{array}{l}\text { Propellant } \\
\text { fill fraction } \\
\qquad \psi_{\mathrm{p}} \\
{[-]}\end{array}$ & $\begin{array}{c}\text { Purge } \\
\text { gas fill } \\
\text { fraction } \\
\psi_{\mathrm{i}} \\
{[-]}\end{array}$ & $\begin{array}{l}\text { Time- } \\
\text { averaged } \\
\text { thrust } \\
F_{\exp } \\
{[\mathrm{N}]}\end{array}$ & $\begin{array}{l}\text { Propellant- } \\
\text { based specific } \\
\text { impulse } \\
I_{\text {sp,exp }} \\
{[\mathrm{s}]}\end{array}$ & $\begin{array}{l}\text { Total-gas-based } \\
\text { specific } \\
\text { impulse } \\
I_{\text {sp,exp,all }} \\
{[\mathrm{s}]}\end{array}$ & $\begin{array}{c}\text { Success } \\
\text { rate } \\
\left(0.9 D_{\mathrm{CJ}}\right) \\
\eta \\
{[\%]}\end{array}$ & $\begin{array}{c}\text { Estimated } \\
\text { suctioned-air } \\
\text { fill fraction at } \\
\chi_{\text {Sato }}=55 \% \\
\psi_{\text {air }} \\
{[-]}\end{array}$ \\
\hline $\mathrm{T}-1$ & 40.0 & 98.6 & 11.8 & 0.93 & 0.295 & 0.274 & 166 & 171 & 153 & 84.7 & 0.194 \\
\hline T-2 & 70.4 & 99.2 & 15.6 & 0.97 & 0.170 & 0.207 & 174 & 179 & 155 & 91.5 & 0.281 \\
\hline T-3 & 99.2 & 102.1 & 12.2 & 0.96 & 0.123 & 0.114 & 239 & 239 & 213 & 75.2 & 0.344 \\
\hline $\mathrm{T}-4$ & 129.6 & 98.7 & 15.9 & 0.99 & 0.091 & 0.113 & 242 & 251 & 216 & 80.8 & 0.357 \\
\hline T-5 & 160.3 & 100.1 & 14.9 & 1.00 & 0.074 & 0.085 & 225 & 230 & 200 & 76.4 & 0.378 \\
\hline
\end{tabular}

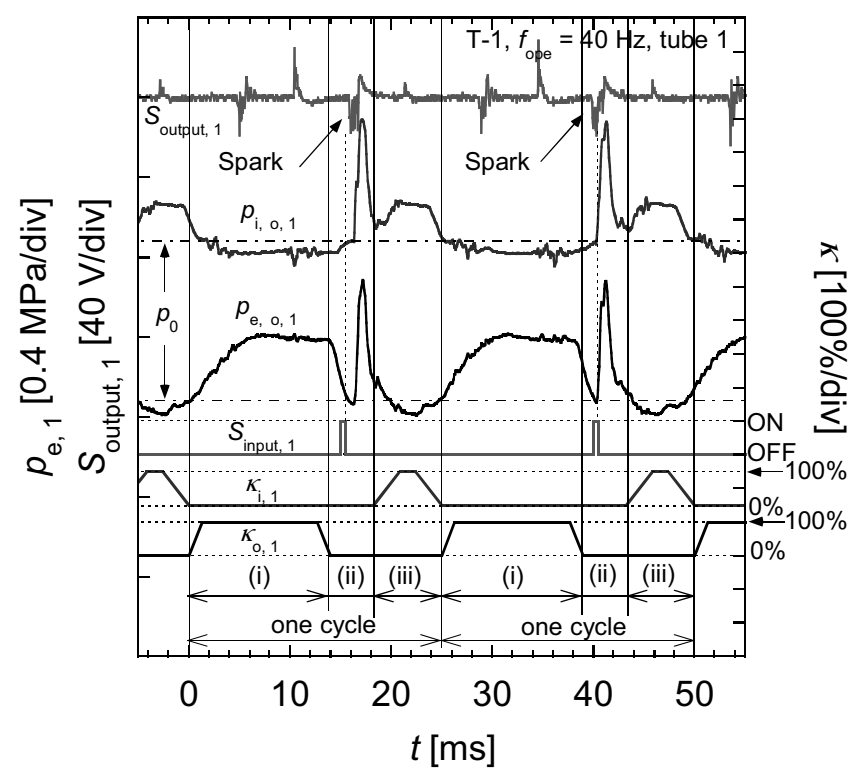

Fig. 6. Results of monitoring valve with valve sequence of tube 1 (T-1, $f_{\text {set }}=40 \mathrm{~Hz}$, tube 1$)$.

0 to process $\mathrm{i}$. The pressure increased to an almost constant value at $t=6.0 \mathrm{~ms}$. At $t=14.2 \mathrm{~ms}\left(\theta=102^{\circ}\right)$, all of the gas-supply ports were closed, and $p_{\mathrm{e}, \mathrm{o}, 1}$ decreased gradually during process ii with the valve closed. After that, the spark output signal, $S_{\text {output, } 1}$, was confirmed in process ii. The exhaust pressures, $p_{\mathrm{e}, \mathrm{o}, 1}$ and $p_{\mathrm{e}, \mathrm{i}, 1}$, increased rapidly upon the arrival of a retonation wave at the pressure gauge ports. ${ }^{24)}$ At $t=18.3 \mathrm{~ms}\left(\theta=132^{\circ}\right)$, the purge gas supply ports began to open, and the constant exhaust pressure of the purge gas, $p_{\mathrm{e}, \mathrm{i}, 1}$, in process iii was confirmed. Finally, at $t=25.0 \mathrm{~ms}$ $\left(\theta=180^{\circ}\right)$, the purge gas port was completely closed, $p_{\mathrm{e}, \mathrm{i}, 1}$ decreased gradually and the oxidizer supply ports of tube 1 began to open again. The oxidizer exhaust pressure, $p_{\mathrm{e}, \mathrm{o}, 1}$, increased gradually when the process went from state 0 to process i, and it shifted smoothly to the next PDRE cycle. The solid and dashed lines in Fig. 7 show the results of monitoring the valve for tubes 1 and 2, respectively. As shown in the figure, a profile with a delay of $12.5 \mathrm{~ms}\left(90^{\circ}\right)$ was confirmed for tube 2 relative to tube 1 , and we confirmed stable valve operation and continuous supply of oxidizer, as designed.

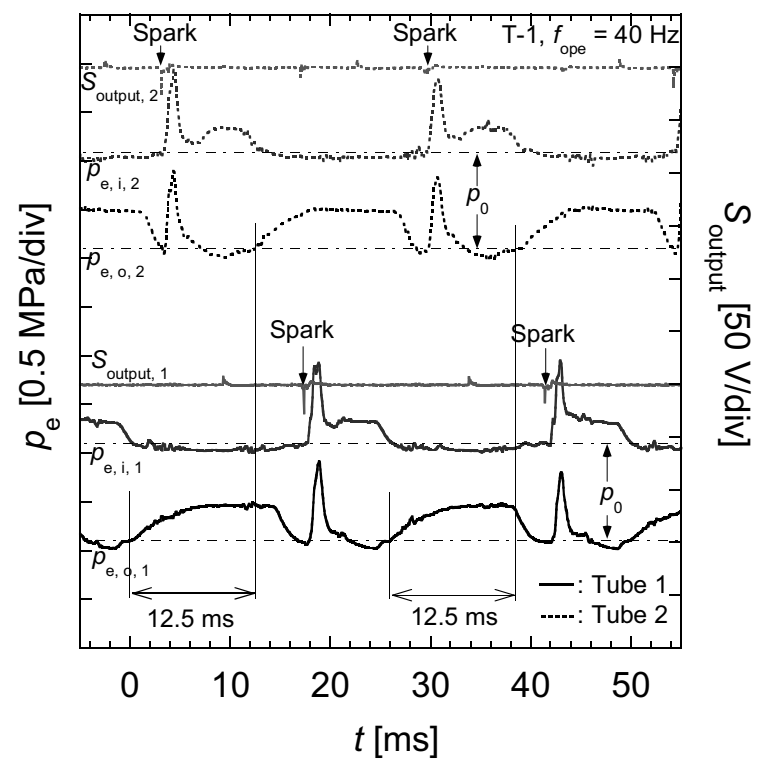

Fig. 7. History of exhaust pressure of oxidizer and purge gas and spark output signals of tubes 1 and $2\left(\mathrm{~T}-1, f_{\text {set }}=40 \mathrm{~Hz}\right.$, solid lines: tube 1 , dashed lines: tube 2).

\subsection{Propellant mass flow rate and fill fraction}

Figure 8 shows the propellant mass flow rate, $\dot{m}_{\mathrm{p}}$, and fill fraction, $\psi_{\mathrm{p}}$, as functions of the operation frequency. $\psi_{\text {plug }}$ in Fig. 8 shows the propellant fill fraction when the propellant filled the tube to the position where the spark plug was installed $\left(\psi_{\text {plug }}=0.01\right)$. The mass flow rate remained within the range of $99.7 \pm 1.3 \mathrm{~g} / \mathrm{s}$, even when the operation frequency changed, because the opening time of the supply port per unit time and the propellant supply pressure were constant. Therefore, the mass per cycle, that is, the fill fraction, decreased when the operation frequency increased.

We found that $92 \%$ of the cyclic combustion waves were accelerated to $0.9 D_{\mathrm{CJ}}$ between the first two ion probes (155 mm and $225 \mathrm{~mm}$ from the end wall). Moreover, as shown in Fig. 6, the rapid increase in the purge gas exhaust pressure was due to the retonation wave, ${ }^{24)}$ and the arrival time after the spark was approximately $300 \mu \mathrm{s}$. According to the results of a visualization experiment carried out by Matsuoka et al.,24) the propagation velocity of the retonation wave was constant at $1,483 \mathrm{~m} / \mathrm{s}$ regardless of the tube width. The DDT time from the spark time and the DDT distance were $187 \mu \mathrm{s}$ and $100 \mathrm{~mm}$, respectively, under conditions 


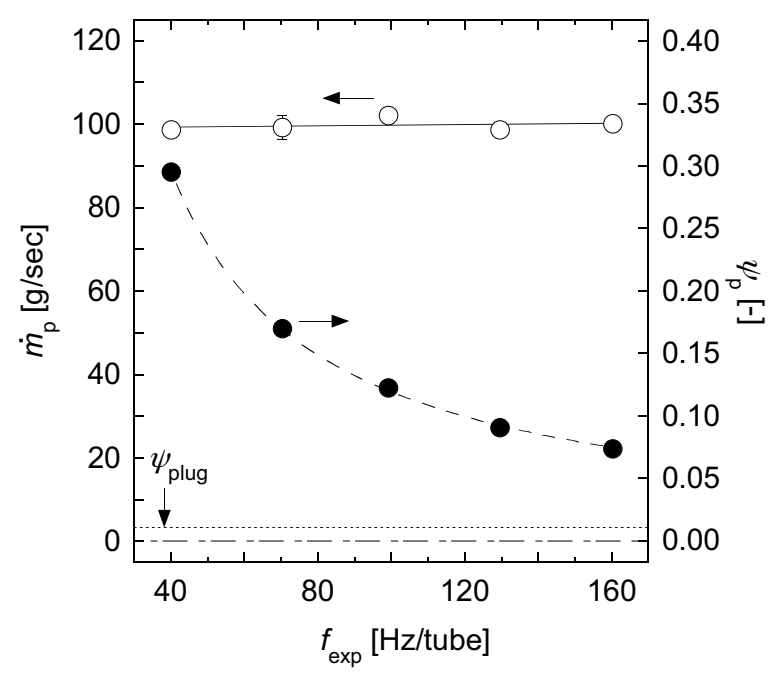

Fig. 8. Propellant mass flow rate and fill fraction.

similar to those in our experiment. Assuming that the propagation velocity of the retonation wave was constant upstream of the combustor, and the DDT time and distance were the same as those in the visualization experiment, the arrival time was evaluated at $327 \mu$ s. This value was within $10 \%$ of the value obtained by monitoring the valve. This suggests that most DDT distances were about $100 \mathrm{~mm}$ from the end wall. The DDT distance of $100 \mathrm{~mm}$ was equivalent to a propellant fill fraction of $\psi_{\mathrm{p}}=0.016$, and the propellant fill fractions under all conditions were sufficiently larger than the DDT distance. In addition, we obtained a propellant mass flow rate that was about three times that achieved with a single-cylinder valve $\left(29.9 \pm 1.6 \mathrm{~g} / \mathrm{s}^{24)}\right)$ under the same supply pressure of $p_{\mathrm{s}}=2 \mathrm{MPa}$ and gas-supply port diameter of $5 \mathrm{~mm}$.

\subsection{Load cell output and time-averaged thrust}

Figure 9 shows the load cell output, $F_{\text {lc }}$, under each set of experimental conditions, where $F_{\text {lc }}$ in Fig. 9 was closest to the average thrust in three experiments carried out under the same conditions. $F_{\text {exp }}$ in Fig. 9 shows the time-averaged thrust defined by Eq. (4). $F_{\text {lc }}$ oscillated until the thrust became constant because the PDRE was connected to a spring, and the average frequency of $2.30 \pm 0.03 \mathrm{~Hz}$ under all conditions was within $8 \%$ of the natural frequency of the test bench $(2.50 \mathrm{~Hz})$. Figure 10 shows the relationship between the propellant fill fraction, $\psi_{\mathrm{p}}$, and the time-averaged thrust, $F_{\text {exp }} \phi$ in Fig. 10 shows the average equivalence ratio. The specific impulse increased with decreasing propellant fill fraction, $\psi_{\mathrm{p}}$, owing to the partial-fill effect. Consequently, the time-averaged thrust, $F_{\text {exp }}$, increased even when the propellant mass flow rate was constant. The ratios of the maximum time-averaged thrust to the valve masses of a single cylinder $^{24)}$ and a four-cylinder PDRE were 8.2 and 32.0, respectively, under the same supply pressure of $2 \mathrm{MPa}$ and gassupply port diameter of $5 \mathrm{~mm}$, and the increase in thrust while maintaining the simplified structure was verified.

\subsection{Propellant-based specific impulse}

When a large mass of inert gas exists downstream of a high-pressure gas, the high-pressure gas has to push out

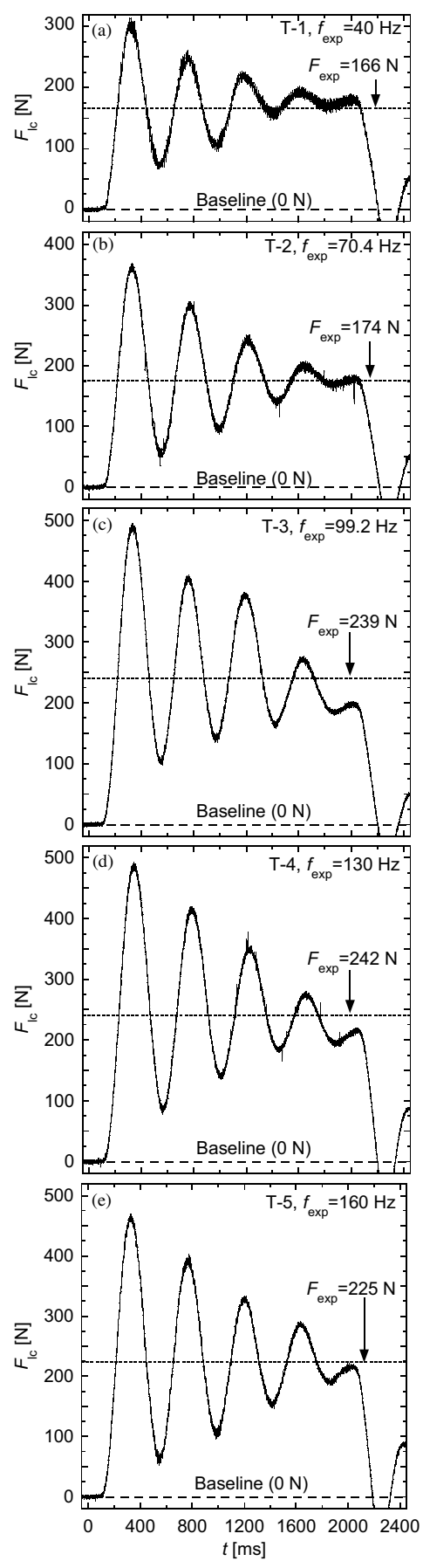

Fig. 9. Load cell output.

the inert gas to enable its expansion. As a result, the expansion of the high-pressure gas becomes slow, and high pressure is exerted on the thrust wall for a longer period of time. This essence of the partial fill effect is explained by considering shock impedance. ${ }^{16,25)}$ If the shock impedance of the driven gas is higher than the detonation wave, the transmitted and reflected waves are both shock waves. The reflected shock wave undergoes repeated reflection between the contact surface and the closed end wall, and the impulse increases. Endo et al. ${ }^{26}$ ) proposed a homogeneous-dilution model in which the exhaust duration was considered. Sato et al. ${ }^{25)}$ proposed a simple model based on a two-dimensional numerical calculation. If a propellant is partially 




Fig. 10. Time-averaged thrust.

filled into a detonation tube and inert gas exists in the remainder of the detonation tube, the specific impulse ratio between the fully filled and partially filled cases is expressed as

$$
\frac{I_{\mathrm{sp}, \mathrm{PF}}}{I_{\mathrm{sp}, \mathrm{FF}}}=\frac{1}{\sqrt{Y}}=\frac{1}{\sqrt{\frac{V_{\mathrm{p}} \rho_{\mathrm{p}}}{V_{\mathrm{p}} \rho_{\mathrm{p}}+\left(V_{\mathrm{t}}-V_{\mathrm{p}}\right) \rho_{\mathrm{I}}}}}
$$

where $I_{\mathrm{sp}, \mathrm{PF}}$ and $I_{\mathrm{sp}, \mathrm{FF}}$ are the propellant-based specific impulses when the detonation tube is partially and fully filled with propellant, respectively. $Y$ is the fraction of the propellant mass per total mass inside the detonation tube. $V$ and $\rho$ are the gas volume and density, respectively, and the subscripts $\mathrm{p}$, I and t denote the propellant, average inert gas and detonation tube, respectively. In this model, the total heat released by combustion is transformed into the kinetic energy of the exhausted gases expressed by the characteristic exhaust velocity. The above equation is obtained when the thermal efficiency (conversion efficiency) under the fully filled condition is equal to that under the partially filled condition. Although the essence of the partial-fill effect is not considered in this semi-empirical formula, this model agrees reasonably well with the experimental values in the range of the propellant fill fraction $\psi_{\mathrm{p}}>0.1$.

We assume that a part of the propellant gas with volume $\alpha V_{\mathrm{t}}\left(0 \leq \alpha V_{\mathrm{t}} \leq V_{\mathrm{p}}\right)$ does not burn because of mixing with the inert gas. In this case, using the propellant fill fraction $\left(\psi_{\mathrm{p}}=V_{\mathrm{p}} / V_{\mathrm{t}}\right)$, Eq. (11) can be changed to

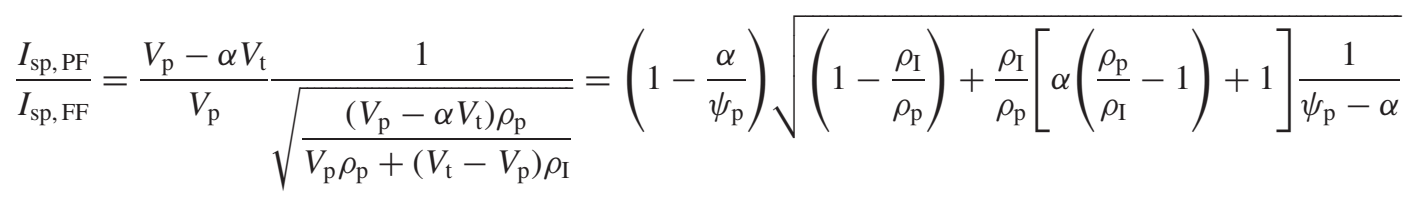

Denoting $V_{\mathrm{p}} / V_{\mathrm{t}}$ by $\psi_{\mathrm{p}}$, the above formula can be written as

$$
\frac{I_{\mathrm{sp}, \mathrm{PF}}}{I_{\mathrm{sp}, \mathrm{FF}}}=\left(1-\frac{\alpha}{\psi_{\mathrm{p}}}\right) \sqrt{\left(1-\frac{\rho_{\mathrm{I}}}{\rho_{\mathrm{p}}}\right)+\frac{\rho_{\mathrm{I}}}{\rho_{\mathrm{p}}}\left[\alpha\left(\frac{\rho_{\mathrm{p}}}{\rho_{\mathrm{I}}}-1\right)+1\right] \frac{1}{\psi_{\mathrm{p}}-\alpha}}
$$

and we can write the following

$$
\frac{\partial}{\partial \psi_{\mathrm{p}}}\left(\frac{I_{\mathrm{sp}, \mathrm{PF}}}{I_{\mathrm{sp}, \mathrm{FF}}}\right)=\frac{\frac{\rho_{\mathrm{I}}}{\rho_{\mathrm{p}}}\left[\alpha\left(\frac{\rho_{\mathrm{p}}}{\rho_{\mathrm{I}}}-1+\frac{2}{\psi_{\mathrm{p}}}\right)-1\right]}{2 \psi_{\mathrm{p}}\left(\psi_{\mathrm{p}}-\alpha\right) \sqrt{\left(1-\frac{\rho_{\mathrm{I}}}{\rho_{\mathrm{p}}}\right)+\frac{\rho_{\mathrm{I}}}{\rho_{\mathrm{p}}}\left[\alpha\left(\frac{\rho_{\mathrm{p}}}{\rho_{\mathrm{I}}}-1\right)+1\right] \frac{1}{\psi_{\mathrm{p}}-\alpha}}}
$$

Therefore, the specific impulse ratio is maximized when

$$
\psi_{\mathrm{p}}=2\left(\frac{1}{\alpha}+1-\frac{\rho_{\mathrm{p}}}{\rho_{\mathrm{I}}}\right)^{-1}
$$

If the ratio is maximized when $\psi_{\mathrm{p}} \approx 0.1$, then

$$
\alpha=\frac{1}{19+\rho_{\mathrm{p}} / \rho_{\mathrm{I}}}
$$

and the maximum value of the ratio is only determined by the density ratio $\rho_{\mathrm{p}} / \rho_{\mathrm{I}}$. As the inert gas, a mixture of purge gas, low-pressure burned gas and suctioned air was considered, and the density ratio was expressed as

$$
\begin{aligned}
\frac{\rho_{\mathrm{p}}}{\rho_{\mathrm{I}}} & =\rho_{\mathrm{p}} \frac{1-\psi_{\mathrm{p}}}{\rho_{\mathrm{i}} \psi_{\mathrm{i}}+\rho_{\mathrm{b}} \psi_{\mathrm{b}}+\rho_{\text {air }} \psi_{\text {air }}} \\
& =\rho_{\mathrm{p}} \frac{1-\psi_{\mathrm{p}}}{\rho_{\mathrm{i}} \psi_{\mathrm{i}}+\rho_{\mathrm{b}}\left(1-\psi_{\mathrm{p}}-\psi_{\mathrm{i}}\right) \chi+\rho_{\mathrm{air}}\left(1-\psi_{\mathrm{p}}-\psi_{\mathrm{i}}\right)(1-\chi)}
\end{aligned}
$$

where

$$
\chi=\frac{\psi_{\mathrm{b}}}{\left(1-\psi_{\mathrm{p}}-\psi_{\mathrm{i}}\right)}
$$

Here the subscripts $b$ and air denote the burned gas and suctioned air from the open end, respectively. The fill fractions $\left(\psi_{\mathrm{p}}, \psi_{\mathrm{i}}\right)$ were obtained from Eqs. (1) and (2), respectively, 
and $\psi_{\mathrm{p}}, \psi_{\mathrm{i}}$ and $\psi_{\text {air }}$ were calculated using each equivalence ratio, ambient pressure and temperature $\left(\rho_{\mathrm{p}} \approx 1.32 \mathrm{~kg} / \mathrm{m}^{3}\right.$, $\rho_{\mathrm{i}} \approx 0.165 \mathrm{~kg} / \mathrm{m}^{3}, \rho_{\text {air }} \approx 1.20 \mathrm{~kg} / \mathrm{m}^{3}$ ). The burned gas was the previous propellant, which isentropically expanded from the Chapman-Jouguet state to atmospheric pressure $\left(\rho_{\mathrm{b}} \approx 0.104 \mathrm{~kg} / \mathrm{m}^{3}\right) .{ }^{27)} \chi$ is the ratio of the burned gas volume to the tube volume after excluding the propellant and purge gas $\left(1-\psi_{\mathrm{p}}-\psi_{\mathrm{i}}\right)$. Air was considered as the inert gas in the first PDRE cycle $\left(\chi=0 \%, \psi_{\mathrm{i}}=0\right)$. In the second and following cycles, purge gas, burned gas and suctioned air were considered as the inert gas. The specific impulses were averaged over the total number of cycles, $f_{\exp } \times t_{\text {ope }}$, as follows:

$$
\frac{I_{\mathrm{sp}, \mathrm{PF}}}{I_{\mathrm{sp}, \mathrm{FF}}}=\frac{1}{I_{\mathrm{sp}, \mathrm{FF}}} \frac{\left(f_{\mathrm{exp}} t_{\mathrm{ope}}-1\right) I_{\mathrm{sp}, \mathrm{PF}, 2 \text { nd }}+I_{\mathrm{sp}, \mathrm{PF}, 1 \mathrm{st}}}{f_{\mathrm{exp}} t_{\mathrm{ope}}}
$$

We estimated the partial-fill effect during multi-pulse operation by varying $\chi$.

A bubble model for single-pulse operation was proposed by Cooper, ${ }^{13)}$ who modeled the one-dimensional expansion process of a high-pressure burned gas in an open shock tube. Kasahara et al. ${ }^{16)}$ compared single-pulse experimental and numerical calculation results using an open shock tube and the bubble model (He and air, $\mathrm{N}_{2}$ and air). When the fill fraction was small $(\psi<0.2)$, the analytical model predicted a maximum specific impulse. The estimated value showed good agreement (within 5\%) with both the numerical computations and experimental results for helium at pressure ratios of 6.0 and 9.2, and was $20 \%$ higher than the experimental value at a pressure ratio of 3.0. The bubble model slightly underpredicted the impulse for nitrogen at a high pressure ratio.

We assumed that the high-pressure burned gas after constant-volume combustion of $\mathrm{C}_{2} \mathrm{H}_{4}-\mathrm{O}_{2}$ mixture (equivalence ratio: 1 , initial pressure: $1 \mathrm{~atm})$ was the drive gas $\left(p_{\mathrm{CV}}=16.8\right.$ atm, $\left.\gamma_{\mathrm{CV}}=1.13, a_{\mathrm{CV}}=1,231.9 \mathrm{~m} / \mathrm{s}^{27)}\right)$ and that a mixture of ambient-pressure burned gas and air $\left(\gamma_{\mathrm{a}}=1.40, a_{\mathrm{a}}=\right.$ $347.2 \mathrm{~m} / \mathrm{s}$ ) was the driven gas. The mixture of ambient-pressure burned gas and air was assumed to be homogeneous at a constant pressure, internal energy and mole number. ${ }^{26)}$ The bubble model was modified to incorporate $\chi$ for multi-pulse operation.

The solid circles $\bullet$ in Fig. 11 show the experimental propellant-based specific impulse, $I_{\mathrm{sp}, \text { exp }}$, and the solid squares $\boldsymbol{\square}$ and triangles $\boldsymbol{\Delta}$ show those for two-cylinder ${ }^{29)}$ and single-cylinder PDREs, ${ }^{24)}$ respectively, using the same-shaped rotary valve. Each value was divided by the propellant-based specific impulse when the detonation tube was fully filled with propellant. Kawane et al. ${ }^{28)}$ investigated the effect of heat and friction loss on the impulse using a ballistic pendulum. The net propellant-based specific impulse of the $\mathrm{C}_{2} \mathrm{H}_{4}$ $\mathrm{O}_{2}$ mixture was $148.5 \mathrm{~s}$ when $L / D$ for the detonation tube was 49 and the initial pressure of the mixture was $1 \mathrm{~atm}$. According to their results, the specific impulse decreased linearly with increasing $L / D$ for $L / D<50$. Our detonation tube $(L / D=44.5)$ was almost identical to Kawane's tube, and



Fig. 11. Relationship between propellant-based specific impulse and propellant fill fraction.

$I_{\mathrm{sp}, \text { FF }}=150 \mathrm{~s}$ and $156 \mathrm{~s}$ were defined as the propellant-based specific impulses in the present study and in a single-cylinder (two-cylinder) PDRE, respectively. $I_{\mathrm{sp}, \mathrm{FF}}=150 \mathrm{~s}$ was $88 \%$ of the theoretical value of $171.2 \mathrm{~s}$ proposed by Endo et al. $\left.{ }^{6}\right)$ The open symbols in Fig. 11 show the values calculated using Eq. (12) under the conditions of $\chi_{\text {sato }}=0 \%$ and 55\%. The horizontal solid lines show the upper limits of the specific impulse obtained from the bubble model under the conditions of $\chi_{\text {bubble }}=90 \%, 70 \%$ and $55 \%$.

As shown in Fig. 11, excluding T-2 and the conditions of a two-cylinder PDRE $\left(\psi_{\mathrm{p}}=0.353, I_{\mathrm{sp}, \exp } / I_{\mathrm{sp}, \mathrm{FF}}=1.01\right)$, the experimental specific impulses were within $\pm 8 \%$ of those obtained using the Sato model with $\chi_{\text {Sato }}=55 \%$. In particular, the results obtained using the model and those obtained in experiments were within $\pm 5 \%$ under the condition of $\psi_{\mathrm{p}}<0.1$ (T-4 and T-5). The experimental values obtained for T-2 and under the condition of the two-cylinder PDRE were $83 \%$ and $89 \%$ of those obtained using the model, respectively. The estimated dilution coefficient $\alpha$ and density ratio $\rho_{\mathrm{p}} / \rho_{\mathrm{I}}$ were $\alpha=4.6 \pm 0.1 \%$ and $2.3 \leq \rho_{\mathrm{p}} / \rho_{\mathrm{I}} \leq 3.0$, respectively. These results suggest that $75 \mathrm{~mL}$ of the propellant ( $4.6 \%$ of the detonation tube volume) was lost by the inert gas. For $\chi_{\text {Sato }}=55 \%$, the fill fraction of the suctioned air was estimated to be $0.194 \leq \psi_{\text {air }} \leq 0.378$ (see Table 2) and increased almost linearly as propellant fill fraction decreased. The experimental specific impulse could be decreased as a result of not only the dilution of propellant in the detonation tube, but also various factors such as propellant dilution in the rotary valve, misfire cycles, and the lack of mixing due to the high-frequency operation and DDT process. Therefore, the estimation of $\psi_{\text {air }}$ is thought to be a lower limit. Kasahara et al. ${ }^{15)}$ carried out a $2.5-8.3 \mathrm{~Hz}$ multi-cycle operation using ethylene-oxygen propellant, a solenoid valve and a large detonation tube $(L / D=22$, $V_{\mathrm{t}}=16.2 \mathrm{~L}$ ), and investigated the partial-fill effect under a low propellant fill fraction $\left(0.075 \leq \psi_{\mathrm{p}} \leq 0.264\right)$. The fill 
fraction of suctioned air was estimated to be $0.175 \leq$ $\psi_{\text {air }} \leq 0.327$ using the Homogeneous-Dilution model of Endo et al. The loss of the specific impulse was not considered in this theoretical model and the quantity of suctioned air was overestimated. However, the fill fraction of suctioned air estimated using the Sato model (lower limit) was in qualitative agreement with Kasahara's results for low-frequency operation and a significant difference due to the operation frequency was not observed.

We compared the results of experiments with those obtained using the bubble model. The upper limit of the specific impulse obtained using the bubble model was 2.14 at $\chi=55 \%, 28 \%$ larger than the maximum value observed in experiments (1.67 for T-4). The bubble model overpredicts the specific impulse for multi-pulse operation. The driven gas is subjected to strong shock-wave compression in actual operation, which is not considered in the bubble model. The drive gas (high-temperature burned gas) is assumed to expand isentropically and uniformly in the model, but the high-temperature burned gas is considered as part of the driven gas. Thus, the speed of the contact surface is not negligible relative to the propagation speed of an acoustic wave that reverberates between the solid thrust surface and the contact surface.

\section{Conclusion}

We proposed a rotary valve appropriate for use with a multi-cylinder PDRE to increase the thrust-to-weight ratio of a PDRE. We constructed a greatly simplified rotary-valved four-cylinder PDRE and evaluated its thrust performance. Stable PDRE operation was confirmed over a wide range of operation frequencies ( $f_{\text {set }}=40-160 \mathrm{~Hz}$ ). A maximum mass flow rate of $102.1 \mathrm{~g} / \mathrm{s}$ was achieved under a propellant supply pressure of $p_{\mathrm{s}, \mathrm{p}}=2 \mathrm{MPa}$, and the partial-fill effect of the propellant was confirmed by varying the operation frequency. The ratio of the maximum time-averaged thrust to the valve mass was about four times that achieved in past single-cylinder PDREs at the same supply pressure (2 MPa) and gas-supply port diameter $(5 \mathrm{~mm})$. We investigated the partial-fill effect of the PDRE under high-frequency operation. The experimental results were compared with those obtained using the improved Sato model with propellant dilution by inert gas. When low-pressure burned gas accounted for $\chi_{\text {Sato }}=55 \%$ of the volume excluding the propellant and purge gas in the detonation tube, the experimental specific impulses were within $\pm 8 \%$ of those obtained using the Sato model apart from under condition T-2 and those of a two-cylinder PDRE $\left(\psi_{\mathrm{p}}=0.353, I_{\mathrm{sp}, \exp } / I_{\mathrm{sp}, \mathrm{FF}}=1.01\right)$. In particular, the model and experiments gave results within $\pm 5 \%$ when the propellant fill fraction was lower than 0.1 (T-4 and T-5). For $\chi_{\text {Sato }}=55 \%$, the estimated dilution coefficient $\alpha$ and the density ratio the propellant to the inert gas $\rho_{\mathrm{p}} / \rho_{\mathrm{I}}$ were $\alpha=4.6 \pm 0.1 \%$ and $2.3 \leq \rho_{\mathrm{p}} / \rho_{\mathrm{I}} \leq 3.0$, respectively. For $\chi_{\text {Sato }}=55 \%$, the fill fraction of suctioned air was estimated to be $0.194 \leq \psi_{\text {air }} \leq 0.378$. A maximum specific impulse of $251 \mathrm{~s}$ and a time-averaged thrust of $242 \mathrm{~N}$ were achieved under an operation frequency of $129.6 \mathrm{~Hz}$ (T-4). The maximum operation frequency was $f_{\exp }=160.3 \mathrm{~Hz} /$ tube $\left(f_{\mathrm{D}}=641.2 \mathrm{~Hz} /\right.$ all tubes $)$.

\section{Acknowledgments}

This study was subsidized by the Research Grant Program from the Institute of Space and Astronautical Science, Japan Aerospace Exploration Agency, a Grant-in-Aid for Scientific Research (A) (No. 24246137) and a Grant-in-Aid for Scientific Research (B) (No. 21360411).

The authors would like to thank Mr. A. Kojima, Mr. T. Sakumi and Mr. K. B. Ikeguchi of the University of Tsukuba for their assistance in performing the experiments.

\section{References}

1) Lee, J. H. S.: The Detonation Phenomena, Cambridge University Press, New York, 2008.

2) Zitoun, R. and Desbordes, D.: Propulsive Performances of Pulsed Detonations, Combust. Sci. Technol., 144 (1999), pp. 93-114.

3) Talley, G. D. and Coy, B. E.: Constant Volume Limit of Pulsed Propulsion for a Constant $\gamma$ Ideal Gas, J. Propul. Power, 18, 2 (2002), pp. 400-406.

4) Kailasanath, K.: Review of Propulsion Applications of Detonation Waves, AIAA J., 38, 9 (2000), pp. 1698-1708.

5) Kailasanath, K.: Recent Developments in the Research on Pulse Detonation Engines, AIAA J., 41, 2 (2003), pp. 145-159.

6) Endo, T., Kasahara, J., Matsuo, A., Inaba, K., Sato, S., and Fujiwara, T.: Pressure History at the Thrust Wall of a Simplified Pulse Detonation Engine, AIAA J., 42, 9 (2004), pp. 1921-1930.

7) Zhdan, S. A., Mitrofanov, V. V., and Sychev, A. I.: Reactive Impulse from the Explosion of a Gas Mixture in a Semiinfinite Space, Combust. Explosion Shock Waves, 30, 5 (1994), pp. 657-663.

8) Cooper, M., Jackson, S., Austin, J., Wintenberger, E., and Shepherd, J. E.: Direct Experimental Impulse Measurements for Detonations and Deflagrations, J. Propul. Power, 18, 5 (2002), pp. 1033-1041.

9) Wintenberger, E., Austin, J. M., Cooper, M., Jackson, S., and Shepherd, J. E.: Impulse of a Single-Pulse Detonation Tube, Graduate Aeronautical Labs., GALCIT Rept. FM00-8, California Institute of Technology, Pasadena, CA, 2002.

10) Schauer, F., Stutrud, J., and Bradley, R.: Detonation Initiation Studies and Performance Results for Pulsed Detonation Engine, AIAA Paper 2001-1129, 2001.

11) Li, C. and Kailasanath, K.: Partial Fuel Filling in Pulse Detonation Engines, J. Propul. Power, 19, 5 (2003), pp. 908-916.

12) Cooper, M., Shepherd, J. E., and Schauer, F.: Impulse Correlation for Partially Filled Detonation Tubes, J. Propul. Power, 20, 5 (2004), pp. 947-950.

13) Cooper, M.: Impulse Generation by Detonation Tubes, Doctoral Thesis, California Institute of Technology, 2004.

14) Kasahara, J., Hasegawa, A., Nemoto, T., Yamaguchi, H., Yajima, T., and Kojima, T.: Performance Validation of a Single-Tube Pulse Detonation Rocket System, J. Propul. Power, 25, 1 (2009), pp. 173-180.

15) Kasahara, J., Hirano, M., Matsuo, A., Daimon, Y., and Endo, T.: Thrust Measurement of a Multi-Cycle Partially Filled Pulse Detonation Rocket Engine, J. Propul. Power, 25, 6 (2009), pp. 1281-1290.

16) Kasahara, J., Liang, Z., Browne, S. T., and Shepherd, J. E.: Impulse Generation by an Open Shock Tube, AIAA J., 46, 7 (2008), pp. 1593-1603.

17) Peraldi, O., Knystautas, R., and Lee, J. H. S.: Criteria for Transition to Detonation in Tubes, Proc. 21st Symp. Combust., 1986, pp. 1629-1637.

18) Shchelkin, K. I. and Troshin, Ya. K.: Gasdynamics of Combustion, Mono Book Corporation, Baltimore, MD, USA, 1965, p. 30.

19) Matsuoka, K., Yageta, J., Nakamichi, T., Kasahara, J., Yajima, T., and Kojima, T.: An Inflow-Driven Valve System for Pulse Detonation Engines, J. Propul. Power, 27, 3 (2011), pp. 597-607. 
20) Golovastov, S. V., Baklanov, D. I., Golub, V. V., Mikushkin, A. Y., Tarasenko, I. N., and Volodin, V. V.: Vibrationless Pulse Detonation Engine, 3rd European Conference for Aerospace Sciences (EUCASS), Versailles, France, 2009.

21) Meholic, G. E.: Rotary Valve for Pulse Detonation Engines, USA Patent Application, No. 6506462 B2, Date of Patent: 14 Jan. 2003.

22) Kojima, T., Sato, T., and Kobayashi, H.: Pulse Detonation Engine and Valve, USA Patent Application, No. 7251928 B2, Date of Patent: 7 Aug. 2007.

23) Bussing, T. R. A.: Rotary Valve Multiple Combustor Pulse Detonation Engine, USA Patent Application, No. 5513489, Date of Patent: 7 May 1996.

24) Matsuoka, K., Esumi, M., Ikeguchi, K. B., Kasahara, J., Matsuo, A., and Funaki, I.: Optical and Thrust Measurement of a Pulse Detonation Combustor with a Coaxial Rotary Valve, Combust. Flame, 159, 3 (2011), pp. 1321-1338.
25) Sato, S., Matsuo, A., Endo, T., and Kasahara, J.: Numerical Studies on Specific Impulse of Partially Filled Pulse Detonation Rocket Engines, J. Propul. Power, 22, 1 (2006), pp. 64-69.

26) Endo, T., Yatsufusa, T., Taki, S., Matsuo, A., Inaba, K., and Kasahara, J.: Homogeneous-Dilution Model of Partially Fueled Simplified Pulse Detonation Engines, J. Propul. Power, 23, 5 (2007), pp. 1033-1041.

27) Reynolds, W. C.: The Element Potential Method for Chemical Equilibrium Analysis: Implementation in the Interaction Program STANJAN: Version 3, Stanford University, TR A-3991, Department of Mechanical Engineering, Stanford, CA, Jan. 1986.

28) Kawane, K., Shimada, S., Kasahara, J., and Funaki, I.: The Influence of Heat Transfer and Friction on the Impulse of a Detonation Tube, Combust. Flame, 158, 10 (2011), pp. 2023-2036.

29) Matsuoka, K.: Flow Control Mechanisms of Detonation Engine, Doctoral Thesis, University of Tsukuba, 2011. 